\title{
Effects of active immunization against oestradiol-17 $\beta$, testosterone or progesterone on receptivity in the female rabbit and evaluation of specificity
}

\author{
F. Elsaesser \\ Institut für Tierzucht und Tierverhalten, FAL, Mariensee, 3057 Neustadt 1, \\ Federal Republic of Germany
}

\begin{abstract}
Summary. Juvenile does were actively immunized against oestradiol-17 $\beta$, testosterone, progesterone or BSA. Depending on the antigen, the antibody titres at 17 weeks ranged between $<1: 10000$ and 1:500 000. Specificity of the antisera was high as judged by cross-reactivity studies. However, significant binding of $\left[{ }^{3} \mathrm{H}\right.$ ]oestradiol-17 $\beta(7-30 \%)$ was observed in 1:100 diluted sera raised against testosterone, and $21-48 \%$ binding of $\left[{ }^{3} \mathrm{H}\right]$ testosterone in sera raised against oestradiol-17 $\beta$ (binding in control animals being 1-8\%). Total serum oestradiol-17 $\beta$ levels (RIA) were not only elevated ( $P \leqslant 0.05$, compared to controls) in does immunized with oestradiol-17 $\beta$ but also in does immunized with testosterone.

Production of antibodies against progesterone did not interfere with receptivity but none of the does gave birth. Receptivity and consequently pregnancy were prevented by immunization against oestradiol-17 $\beta$, suggesting that oestrogen is necessary for receptivity in the rabbit. Receptivity was also blocked in does immunized against testosterone. It is suggested that this is a non-specific effect and a consequence of oestradiol inactivation due to increased binding in serum.
\end{abstract}

\section{Introduction}

Active immunization with steroid-protein conjugates has been extensively used to raise antibodies for radioimmunoassay. In addition, active or passive immunization with steroid hormones has been employed as a tool in reproduction research (see Nieschlag \& Wickings, 1976). Immunization with gonadal steroids might be considered as 'selective immunological gonadectomy', because of the biological neutralization effect, and this technique offers the theoretical advantage over castration and steroid replacement that the hypothalamo-pituitarygonadal axis remains complete and the physiological role of a single gonadal hormone can be studied in an otherwise unchanged steroid spectrum. The problem, however, in studies involving immunization with steroids, is the specificity of the immune response which must be carefully evaluated. Determinations of specificity by cross-reactivity studies in vitro are far from ideal, because the situation in vivo might be quite different.

The subject of this paper was to study, by using active immunization procedures, the particular role of oestradiol-17 $\beta$, testosterone and progesterone in the control of lordosis behaviour in the female rabbit, in which oestradiol-17 $\beta$ is supposed to be the only hormone responsible for receptivity (McDonald, Vidal \& Beyer, 1970). A further purpose was to evaluate the specificity of the effects by comparing cross-reactivity and steroid binding of tritium-labelled steroids. 


\section{Materials and Methods}

\section{Immunization procedure}

Juvenile does $(3-5 \mathrm{~kg})$, housed in individual cages under natural daylight, were immunized intradermally in two consecutive experiments (see Table 1) with $200 \mu \mathrm{g}$ steroid conjugate as described by Vaitukaitis, Robbins, Nieschlag \& Ross (1971). The animals in Exp. 1 were crossbreds from our own colony and those in Exp. 2 were chinchilla rabbits. Subcutaneous and intramuscular booster injections of $200 \mu \mathrm{g}$ antigen were given 7 and 11 weeks after the first immunization. Blood samples were taken by puncturing an ear vein at weekly intervals from the 7 th to 17 th week of the experiment.

\section{Antibody titres and antibody specificity}

The titre of the antiserum was determined by using a dextran-coated charcoal radioimmunoassay technique (Elsaesser, Parvizi \& Ellendorff, 1978). The specificity of the immune response was tested in vitro by determination of cross-reactivity (Abraham, 1974) and of steroid binding in serum. To evaluate steroid binding, tritiated steroids (8000-10 000 c.p.m., about $30 \mathrm{pg}$ ) were incubated overnight at $4{ }^{\circ} \mathrm{C}$ with antiserum diluted $1: 100$ with buffer. Percentage binding was determined after separation with dextran-coated charcoal.

\section{Hormone analysis}

Serum oestradiol- $17 \beta$ and progesterone levels were measured by specific radioimmunoassay without prior chromatography as described previously by Elsaesser et al. (1978) and Parvizi, Elsaesser, Smidt \& Ellendorff (1976), respectively, except that the antiserum (P/3) was raised against progesterone-11 $\alpha$-bovine serum albumin by intradermal immunization in a rabbit and was diluted 1:20 000. The antibody cross-reacted $3.2 \%$ with desoxycorticosterone, $\leqslant 0.3 \%$ with testosterone, and $\leqslant 0.1 \%$ with $17 \alpha$-hydroxyprogesterone, hydrocortisone and oestradiol- $17 \beta$. Procedural losses were corrected by incubation for $30 \mathrm{~min}$ at room temperature with tritiumlabelled steroids before extraction. The inter- and intra-assay coefficients of variation were $13 \cdot 3$ and $9.0 \%$ respectively for the determination of oestradiol- $17 \beta$ and 14.1 and $9.9 \%$ respectively for the determination of progesterone.

\section{Effects on receptivity and pregnancy}

Receptivity was tested by daily exposure (minimum $5 \mathrm{~min}$ ) of the does to a fertile male between the 18th and 22nd week after the first immunization injection. Four males were used in turns and males that mated were not used again the same day.

\section{Statistical analysis}

Differences in hormone levels between treatment groups were determined using two-way analysis of variance for unbalanced data (Snedecor, 1956).

\section{Results}

As can be seen from Table 1 , immunization with oestradiol-17 $\beta$ prevented receptivity and consequently pregnancies. In animals immunized with testosterone, receptivity and parturition were observed in 2 does (Exp. 1) which had low antiserum titres. In Exp. 2, 1 animal immunized against testosterone was repeatedly mated, but did not give birth. Immunization with progesterone had no effect on receptivity, but no litters were obtained. 
Table 1. Effect of immunization with gonadal steroids on receptivity and pregnancy in rabbits

\begin{tabular}{|c|c|c|c|c|}
\hline Exp. & Treatment & $\begin{array}{l}\text { No. of } \\
\text { rabbits } \\
\text { tested }\end{array}$ & $\begin{array}{l}\text { No. } \\
\text { receptive }\end{array}$ & $\begin{array}{c}\text { No. giving } \\
\text { birth }\end{array}$ \\
\hline 1 & Untreated control & 7 & 7 & 6 \\
\hline 2 & Untreated control & 5 & 5 & 4 \\
\hline 2 & Bovine serum albumin (BSA) & 6 & 6 & 6 \\
\hline 1 & Oestradiol-17ß-6-CMO-BSA (Ikapharm) & 3 & 0 & 0 \\
\hline 2 & Oestradiol-17 $\beta-6-\mathrm{CMO}-\mathrm{BSA}$ (Ikapharm) & 8 & 1 & 0 \\
\hline 1 & Testosterone-3-CMO-BSA (Ikapharm) & 4 & 2 & 1 \\
\hline 2 & Testosterone-3-CMO-BSA (Steraloids) & 6 & 1 & 0 \\
\hline 1 & Progesterone-1 $1 \alpha-\mathrm{OH}-\mathrm{BSA}$ (Ikapharm) & 6 & 6 & 0 \\
\hline
\end{tabular}

Differences in the development of antibody titres are shown in Text-fig. 1. The specificity of the antisera tested was high, as judged by the results of the cross-reactivity studies (Table 2). However, in-vitro binding (Table 3) of tritium-labelled steroids in sera diluted 1:100 revealed a much lower degree of specificity. However, these figures do not give an estimate of the biologically active fraction. The steroid hormone levels after immunization (Table 2 ) show that total (bound and free) serum oestradiol- $17 \beta$ levels were not only elevated $(P \leqslant 0.05$ compared to controls) in does immunized with oestradiol-17 $\beta$, but also in does immunized with testosterone. In the animals immunized with oestradiol-17 $\beta$, serum oestradiol-17 $\beta$ values were 20 times higher than those in the control does $(P \leqslant 0.001)$. Progesterone levels were significantly elevated $(P<$ 0.05 ) in sera of animals immunized with progesterone.

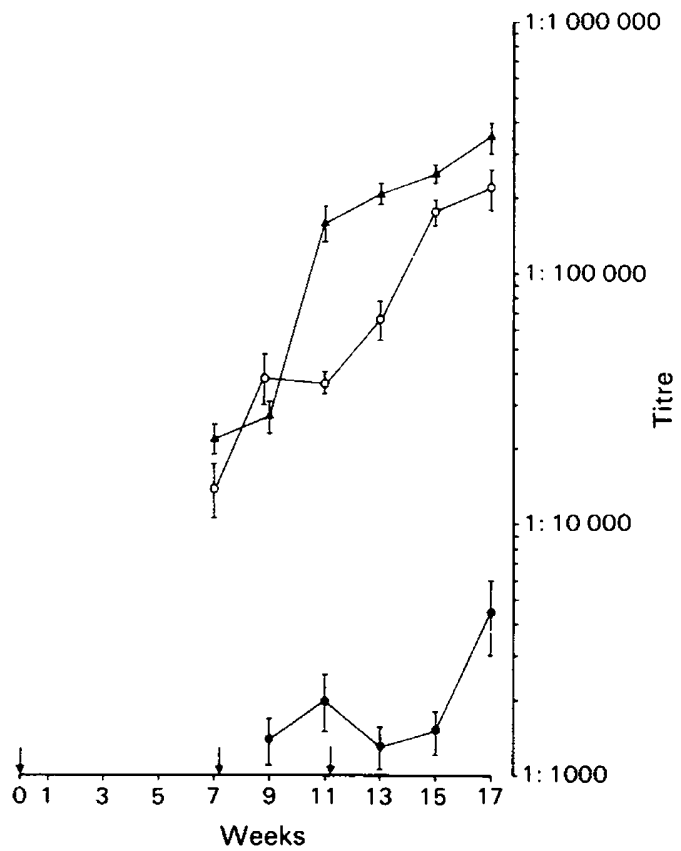

Text-fig. 1. Development of antibody titres (mean \pm s.e.m., logarithmic scale) in the course of immunization of female rabbits injected with $200 \mu \mathrm{g}(\downarrow)$ progesterone $(0$, Exp. $1, N=6)$, oestradiol-17 $\beta$ (O, Exp. 2, $N=8$ ) or testosterone ( $\Delta$, Exp. 2, $N=6$ ). 

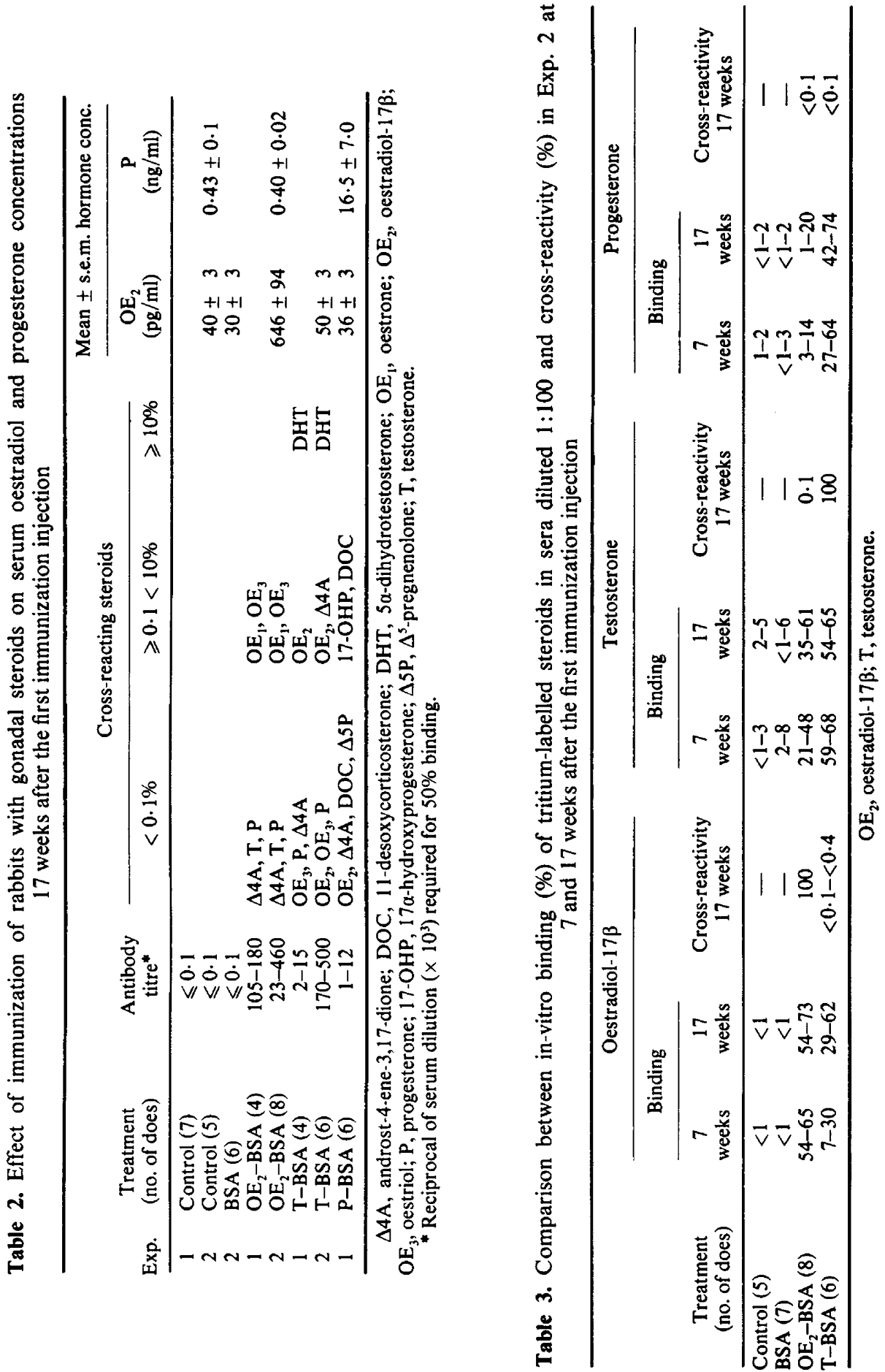


\section{Discussion}

When using immunization techniques as a tool in reproduction research, it is of utmost importance for the interpretation of the results to characterize the specificity of the antibodies produced. It has been pointed out by Niswender (1975) that specificity, as defined by radioimmunoassay techniques, is not the best way of characterizing an antiserum for in-vivo neutralization, since in this system only the population of high-affinity antibodies is selected, and these may amount to only $1-2 \%$ of the total population and be of minor importance in the invivo neutralization. The specificity of the antisera we used was therefore assessed by two different methods. According to the cross-reaction studies, the antisera raised had a marked degree of specificity, recommending them for use in radioimmunoassay procedure. However, binding of sera diluted 1:100 to various tritiated steroids, which is considered to be more close to the in-vivo situation, raises doubts about the specificity of the effects observed following active immunization with steroids and might explain the interesting finding that immunization with steroids resulted not only in an elevation of total serum (bound and free) concentrations of the steroid used as the antigen, but also of other steroids. For example, elevated oestradiol levels were found in animals immunized against testosterone and we assume that this was caused by the non-specific increase of oestradiol-17 $\beta$ binding in the serum of these animals. We did not attempt to determine the unbound fraction, i.e. the biologically active fraction, by equilibrium dialysis, as even this method is not reliable regarding the amount of steroids bound in undiluted serum when measuring very high binding (Nieschlag, Usadel, Wickings, Kley \& Wuttke, 1975; Thorneycroft, Thorneycroft, Scaramuzzi \& Blake, 1975). However, from the effect of immunization on receptivity and fertility it is evident that the amount of unbound, biologically active hormones has been reduced.

The rabbit appears to be one of the few non-primate mammals in which sexual activity may continue after ovariectomy (Beyer, Cruz \& Rivaud, 1969). In this study, receptivity and consequent pregnancy was prevented by immunization against oestradiol- $17 \beta$, most probably due to a biological neutralization of oestradiol- $17 \beta$ or other oestrogen. This suggests that oestrogen is necessary for receptivity in the rabbit. This conclusion is substantiated by the experiments of McDonald et al. (1970), who found that sexual receptivity in ovariectomized female rabbits could be restored by treatment with oestradiol benzoate. The effects of active immunization against progesterone can be explained by the recent report of French (1977) that progesterone is essential for embryo survival, and further indicate that this hormone is not necessary for the expression of sexual behaviour in the rabbit.

In Exp. 2, receptivity was blocked in 5/6 does immunized against a testosterone conjugate with a steroid-protein molar ratio of more than $20: 1$ which gave rise to very high antibody titres. This cer uinly contradicts the reports of Bidlingmaier, Knorr \& Neumann (1977) and of Armstrong, Gauldie \& YoungLai (1978) and the reason for these divergent findings might be that the antibody titres were about 10 times higher in our animals.

The finding that receptivity was also blocked in does immunized against testosterone must be interpreted with caution in view of the high binding of oestradiol in the serum of these animals and the observation that oestrous behaviour may be restored in the ovariectomized rabbit by injection of testosterone, but not by treatment with the non-aromatizable androgen $5 \alpha$ dihydrotestosterone (McDonald et al., 1970; Beyer, McDonald \& Vidal, 1970). It is suggested that in these animals the suppression of receptivity is a non-specific effect and a consequence of oestradiol inactivation due to increased binding in serum.

We conclude that the specificity of the observed response following active immunization is a major problem. Non-specific increase of steroid binding in serum has been observed in all animals immunized against gonadal steroids and it is difficult to evaluate the importance of this effect. Steroid hormones such as oestradiol-17 $\beta$ which occur in low concentrations in the blood may be neutralized, but others may not be affected in their biological activity. An alternative 
possibility in studies involving immunization procedures as a tool in biological research would be to use purified antibodies for passive immunization procedures.

This work was supported by the Deutsche Forschungsgemeinschaft. Some of the results are part of the M.D. dissertation of W. Lange (Göttingen, 1978). Regina Ronge provided expert technical assistance.

\section{References}

Abraham, G.E. (1974) Radioimmunoassay of steroids in biological materials. Acta endocr., Copenh. Suppl. 183, $7-42$.

Armstrong, R.W., Gauldie, J. \& YoungLai, E.V. (1978) Effects of active immunization of female rabbits against testosterone. J. Endocr. 79, 339-347.

Beyer, C., Cruz, M.L. \& Rivaud, N. (1969) Persistence of sexual behaviour in ovariectomized, adrenalectomized rabbits treated with cortisol. Endocrinology 85, 790-793.

Beyer, C., McDonald, P. \& Vidal, N. (1970) Failure of $5 \alpha$-dihydrotestosterone to elicit estrous behaviour in the ovariectomized rabbit. Endocrinology 86, 939941 .

Bidlingmaier, F., Knorr, D. \& Neumann, F. (1977) Inhibition of masculine differentiation in male offspring of rabbits actively immunised against testosterone before pregnancy. Nature, Lond. 266, 647648.

Elsaesser, F., Parvizi, N. \& Ellendorff, F. (1978) Steroid feedback on luteinizing hormone secretion during sexual maturation in the pig. J. Endocr. 78, 329-342.

French, L.R. (1977) Effects of antibodies to progesterone on early pregnancy in rabbits. Biol. Reprod. 16, 363369.

MeDonald, P., Vidal, N. \& Beyer, C. (1970) Sexual behaviour in the ovariectomized rabbit after treatment with different amounts of gonadal hormones. Horm. Behav. 1, 161-172.

Nieschlag, E. \& Wickings, E.J. (1976) Immunisation with hormones in reproduction research. In Proc. 5th
Int. Congr. Endocrinology, Hamburg, Vol. 1, pp. 386-390. Ed. V. H. T. James. Excerpta Medica (ICS No. 402), Amsterdam.

Nieschlag, E., Usadel, K.H., Wickings, E.J., Kley, H.K. \& Wuttke, W. (1975) Effects of active immunization with steroids on endocrine and reproductive functions in male animals. In Immunization with Hormones in Reproduction Research, pp. 155-170. Ed. E. Nieschlag. North-Holland Publishing Company, Amsterdam.

Niswender, G.D. (1975) In Immunization with Hormones in Reproduction Research, p. 153 (discussion remarks). Ed. E. Nieschlag. North-Holland Publishing Company, Amsterdam.

Parvizi, N., Elsaesser, F., Smidt, D. \& Ellendorff, F. (1976) Plasma luteinizing hormone and progesterone in the adult female pig during the oestrous cycle, late pregnancy and lactation, and after ovariectomy and pentobarbitone treatment. J. Endocr. 69, 193-203.

Snedecor, G.W., (1956) Statistical Methods, section 11, p. 291. Iowa State University Press, Ames.

Thorneycroft, I.H., Thorneycroft, N.K., Scaramuzzi, R.J. \& Blake, Ch.A. (1975) Radioimmunoassay of serum $\mathrm{LH}$ and testosterone in male rabbits actively immunized against testosterone. Endocrinology 97, 301-306.

Vaitukaitis, J., Robbins, J. B., Nieschlag, E. \& Ross, G.T. (1971) A method for producing specific antisera with small doses of immunogen. J. clin. Endocr. Metab. 33, 988-991. 